\title{
Expression of sialyl-Tn sugar antigen in bladder cancer cells affects response to Bacillus Calmette Guérin (BCG) and to oxidative damage
}

\author{
Paulo F. Severino ${ }^{1,3, *}$, Mariana Silva ${ }^{1, *}$, Mylene Carrascal $^{1}$, Nadia Malagolini ${ }^{3}$, \\ Mariella Chiricolo ${ }^{3}$, Giulia Venturi ${ }^{3}$, Annalisa Astolfi ${ }^{4}$, Mariangela Catera ${ }^{3}$, Paula A. \\ Videira $^{1,2}$ and Fabio Dall'Olio ${ }^{3}$ \\ ${ }^{1}$ Centro de Estudos de Doenças Crónicas, CEDOC, NOVA Medical School, Faculdade de Ciências Médicas, Universidade NOVA \\ de Lisboa, Lisboa, Portugal \\ ${ }^{2}$ UCIBIO, Departamento Ciências da Vida, Faculdade de Ciências e Tecnologia, Universidade NOVA de Lisboa, Lisboa, Portugal \\ ${ }^{3}$ Dipartimento di Medicina Specialistica, Diagnostica e Sperimentale, Sede di Patologia Generale, Università di Bologna, Bologna, Italy \\ ${ }^{4}$ Centro Interdipartimentale Ricerche sul Cancro "Giorgio Prodi", Università di Bologna, Bologna, Italy \\ * Co-first authors \\ Correspondence to: Fabio Dall'Olio, email: fabio.dallolio@unibo.it \\ Paula A. Videira, email: p.videira@fct.unl.pt
}

Keywords: Bacillus Calmette-Guérin, bladder cancer, glycosylation, sialyl-Tn antigen, ST6GALNAC 1 sialyltransferase

Received: May 30, $2016 \quad$ Accepted: March 30, $2017 \quad$ Published: April 17, 2017

Copyright: Severino et al. This is an open-access article distributed under the terms of the Creative Commons Attribution License 3.0 (CC BY 3.0), which permits unrestricted use, distribution, and reproduction in any medium, provided the original author and source are credited.

\section{ABSTRACT}

The sialyl-Tn (sTn) antigen is an 0 -linked carbohydrate chain aberrantly expressed in bladder cancer (BC), whose biosynthesis is mainly controlled by the sialyltransferase ST6GALNAC1. Treatment with Bacillus Calmette-Guérin (BCG) is the most effective adjuvant immunotherapy for superficial $B C$ but one third of the patients fail to respond. A poorly understood correlation between the expression of sTn and BC patient's response to BCG was previously observed. By analyzing tumor tissues, we showed that patients with high ST6GALNAC1 and IL-6 mRNA expression were BCG responders. To investigate the role of STn in BC cell biology and BCG response, we established the cell lines $M C R_{\text {STn }}$ and $M C R_{N c}$ by retroviral transduction of the BC cell line MCR with the ST6GALNAC1 CDNA or with an empty vector, respectively. Compared with MCR $_{\mathrm{Nc}^{\prime}} \mathrm{BCG}-$ stimulated MCR $_{\text {STn }}$ secreted higher levels of IL-6 and IL-8 and their secretome induced a stronger IL-6, IL-1 $\beta$, and TNFa secretion by macrophages, suggesting the induction of a stronger inflammatory response. Transcriptomic analysis of $\mathbf{M C R}_{\mathrm{Nc}}$ and $\mathbf{M C R}_{\mathrm{STn}}$ revealed that ST6GALNAC1/sTn expression modulates hundreds of genes towards a putative more malignant phenotype and down-regulates several genes maintaining genomic stability. Consistently, $\mathbf{M C R}_{\text {sTn }}$ cells displayed higher $\mathrm{H}_{2} \mathrm{O}_{2}$ sensitivity. In $\mathbf{M C R}_{\text {stn, }}$ BCG challenge induced an increased expression of several regulatory non coding RNA genes. These results indicate that the expression of ST6GALNAC1/sTn improves the response to BCG therapy by inducing a stronger macrophage response and alters gene expression towards malignancy and genomic instability, increasing the sensitivity of BC cells to the oxidizing agents released by BCG.

\section{INTRODUCTION}

Intravesical inoculation with Bacillus CalmetteGuérin (BCG) is an effective adjuvant therapy for treating non-muscle invasive bladder cancer (BC). However, a significant number of patients fails to respond. Although the precise mechanisms of its action remains uncertain, it is clear that BCG is internalized by cancer cells and induces 
a local inflammatory response, which is responsible for the anti-tumor effect [1-3]. Moreover, oxidizing agents released by BCG play a key role in the killing of BC cells [4]. A comprehensive understanding of how BCG modulates the immune system and induces phenotypic changes of $\mathrm{BC}$ could greatly improve patient's treatment.

Aberrant glycosylation of proteins is a common feature of several cancers $[5,6]$, including $\mathrm{BC}$ [710], and is often caused by the deregulation of glycosyltransferases, the enzymes which build the sugar portions of glycoconjugates. Several tumorassociated-antigens arise from deregulated glycosylation. Specifically, the tumor-associated-antigen sialyl-Tn (sTn) is a disaccharide $O$-glycosidically linked to serine or threonine, whose biosynthesis is mainly controlled by its cognate sialyltransferase ST6GALNAC1 (Figure 1) $[9,11,12]$. sTn is aberrantly expressed by a variety of human cancers, affecting their invasive potential [13-17]. Several reports have demonstrated that BC patients frequently overexpress this antigen and a correlation with an increased activity of ST6GALNAC1 has been consistently found $[9,13]$. Furthermore, sTnantigen-positive $\mathrm{BC}$ patients exhibit enhanced risk of recurrence and progression [9, 18]. Conversely, BC patients expressing the sTn and/or the related antigen sialyl-6-T (Figure 1) show a better response to BCG immunotherapy. Thus, sTn expression induces a more aggressive phenotype but a better clinical response to $\mathrm{BCG}$, although the mechanisms underlying these biological effects remain to be elucidated.

In the present study, we compared ST6GALNAC1 and $I L-6$ gene expression in BC tissue from BCG responder and non-responder patients and showed that high ST6GALNAC1 mRNA expressing patients were $\mathrm{BCG}$ responders and had the tendency to express higher levels of IL-6 mRNA. In BC cells overexpressing or not ST6GALNAC1 and its cognate sTn antigen, we studied cytokine secretion after BCG-challenge and their ability to stimulate inflammatory responses by macrophages. In addition, we characterized the transcriptome modulation induced by sTn expression and/or by BCG challenge in $\mathrm{BC}$ cells. Interestingly, we observed in sTn-expressing cells the down-regulation of several genes involved in maintaining genomic stability and, consistently, an increased sensitivity to the oxidizing activity of $\mathrm{H}_{2} \mathrm{O}_{2}$.

\section{RESULTS}

\section{ST6GALNAC1 and IL-6 expression is associated with a better response to $B C G$}

We analyzed the expression of ST6GALNAC1 mRNA in matched tissues of normal urothelium and bladder cancer from $43 \mathrm{BC}$ patients before BCG therapy. As shown in Figure 2A, the tumor tissue of a group of patients showed a very high ST6GALNAC1 mRNA expression. All these patients displayed good BCG response (Figure 2B), suggesting that ST6GALNAC1 mRNA overexpression identifies a group of patients with propensity to BCG response. In addition, the expression level of the IL-6 gene was also higher in BCG-responder patients (Figure 2C). Correlation analysis indicated a significant $(\mathrm{r}=0.375 ; \mathrm{p}=0.04)$ relationship between ST6GALNAC1 and IL-6 expression in the responders group (Figure 2D) but not in the non-responders group $(r=0.281 ; p=0.33)$, suggesting that patients with higher ST6GALNAC1 expression have the tendency to express higher levels of IL-6.

\section{sTn expression promotes pro-inflammatory cytokine secretion by $\mathrm{BC}$ cells}

We studied ST6GALNAC1-transduced cell line $\mathrm{MCR}_{\mathrm{sTn}}$, which comprises more than $95 \%$ of sTn-positive cells and expresses high levels of ST6GALNAC1 mRNA and enzyme activity, as previously reported [9]. Its respective negative control $\left(\mathrm{MCR}_{\mathrm{Nc}}\right)$ obtained by transduction with an empty vector expressed, like the wild type untransduced MCR cell line, negligible levels of the sTn antigen and of ST6GALNAC1 mRNA and enzyme activity $[9,13]$.

To evaluate the effect of ST6GALNAC1 expression by $\mathrm{BC}$ cells on the induction of an inflammatory response triggered by BCG stimuli, the secretion of 10 cytokines (listed in Materials and Methods) was measured in conditioned media of $\mathrm{MCR}_{\mathrm{Nc}}$ or $\mathrm{MCR}_{\mathrm{sTn}}$, challenged or not with BCG. Preliminarily, the internalization of BCG by $\mathrm{MCR}_{\mathrm{Nc}}$ or $\mathrm{MCR}_{\mathrm{sTn}}$ was assessed by flow cytometry and found to be proportional to incubation time but not statistically different in the two cell populations for incubation times up to $6 \mathrm{~h}$ (data not shown), in agreement with previous results [10]. Of the cytokines tested, only IL-6 and IL- 8 secretion was detectable. While both MCR and $\mathrm{MCR}_{\mathrm{sTn}}$ cells natively produced high levels of IL-6, only MCRsTn cells significantly upregulated IL-6 secretion after BCG challenge (Figure 3 and Supplementary Table 1). In contrast, secretion of IL-8 was almost negligible in unchallenged cells but dramatically raised in both $\mathrm{MCR}_{\mathrm{Nc}}$ and $\mathrm{MCR}_{\mathrm{sTn}}$ cells after BCG challenge. Secretion of IL-8 after BCG challenge was also significantly higher in $\mathrm{MCR}_{\mathrm{sTn}}$ cells than in $\mathrm{MCR}_{\mathrm{Nc}}$ (Figure 3 and Supplementary Table 1). Altogether, these data suggest that the expression of ST6GALNAC1 and of its cognate sTn by BC promote the release of pro-inflammatory cytokines after BCG stimuli, crucial for the polarization and recruitment of inflammatory cells to BC sites.

\section{sTn expression by BC cells induces a stronger macrophage secretory response after BCG stimuli}

We next assessed the role played by BCGstimulated BC cells differentially expressing sTn on the first line of innate immunity, by analyzing 
the macrophage response induced. For that, human macrophages differentiated from the monocytes of healthy blood donors were stimulated for $24 \mathrm{~h}$ with the conditioned media from BCG-challenged or unchallenged $\mathrm{MCR}_{\mathrm{Nc}}$ or $\mathrm{MCR}_{\mathrm{STn}}$ cells and the production of various cytokines was measured in their culture medium (Figure 4). After stimulation with conditioned medium from unchallenged $\mathrm{MCR}_{\mathrm{Nc}}$ or $\mathrm{MCR}_{\mathrm{sTn}}$ cell lines, macrophages de novo produced IL-6 and TNF $\alpha$, while the basal cytokine secretion of IL-1 $\beta$ and IL-10 remained unchanged (Figure 4 and Supplementary Table 1). Interestingly, when stimulated with the conditioned medium from BCG-challenged $\mathrm{MCR}_{\mathrm{Nc}}$ or $\mathrm{MCR}_{\mathrm{sTn}}$ cell lines, macrophages significantly increased secretion of IL-6, IL-1 $\beta$, TNF- $\alpha$ and IL-10 but not of IL-8 (Figure 4 and Supplementary Table 1). Notably, the induction of cytokine secretion was markedly upregulated when macrophages were stimulated with the conditioned medium from BCG-challenged $\mathrm{MCR}_{\mathrm{sTn}}$ cells, compared to those stimulated with BCG-challenged $\mathrm{MCR}_{\mathrm{Nc}}$. The cytokines IL-2, IL-4, IL-12, and IL-17 were never detected in any condition (data not shown).

Collectively, data suggests that the secretome of cells overexpressing sTn, when stimulated with BCG, induce a higher expression of pro-inflammatory cytokines such as IL-6 and TNF- $\alpha$.

\section{ST6GALNAC1 overexpression by BC cells promotes down-regulation of genes responsible for maintaining genomic stability}

The overall impact of ST6GALNAC1 expression on the transcriptome of MCR cells was analyzed by expression microarray technology on both $\mathrm{MCR}_{\mathrm{sTn}}$ and $\mathrm{MCR}_{\mathrm{Nc}}$ cells.

Considering only genes modulated at least by a $\log _{2}$ expression difference $\geq 1.0$ (which means a change of at least 2 folds), 488 genes were modulated as a consequence of ST6GALNAC1 overexpression. Of these, 185 displayed up-regulation and 303 downregulation in $\mathrm{MCR}_{\mathrm{sTn}}$ compared to $\mathrm{MCR}_{\mathrm{Nc}}$. The complete list of genes showing significant modulation is reported in Supplementary Table 2.

While several genes were found to be modulated by ST6GALNAC1, we focused our attention on genes with a recognized role in tumor growth and progression, owing the well-known role of sTn in cancer growth. Therefore, we identified 21 genes, whose up- or downregulation in $\mathrm{MCR}_{\mathrm{sTn}}$ could, according to literature data, play a putative role in promoting or inhibiting cancer growth. The proportion between cancer genes modulated toward increased or decreased malignancy was 14 to 7 , respectively. The cellular functions on which the
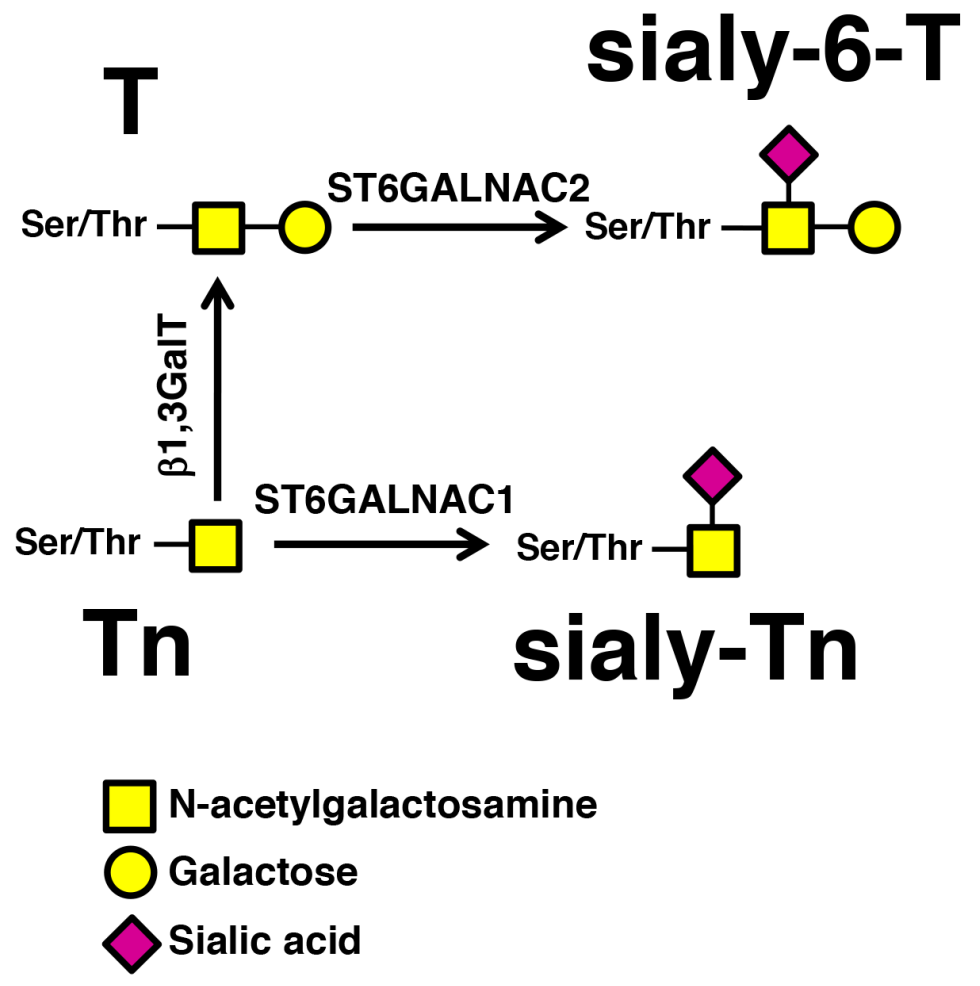

Figure 1: Biosynthesis of sTn by ST6GALNAC1. The addition of $\alpha 2,6$-linked sialic acid on the Tn antigen (GalNAc-Ser/Thr), mediated by ST6GALNAC1 results in the biosynthesis of the sTn antigen, while the addition of $\alpha 2,6$-linked sialic acid on the T antigen (Galß1,3GalNAc-Ser/Thr), resulting in the biosynthesis of the sialyl-6-T antigen, is catalyzed mainly by ST6GALNAC2. 

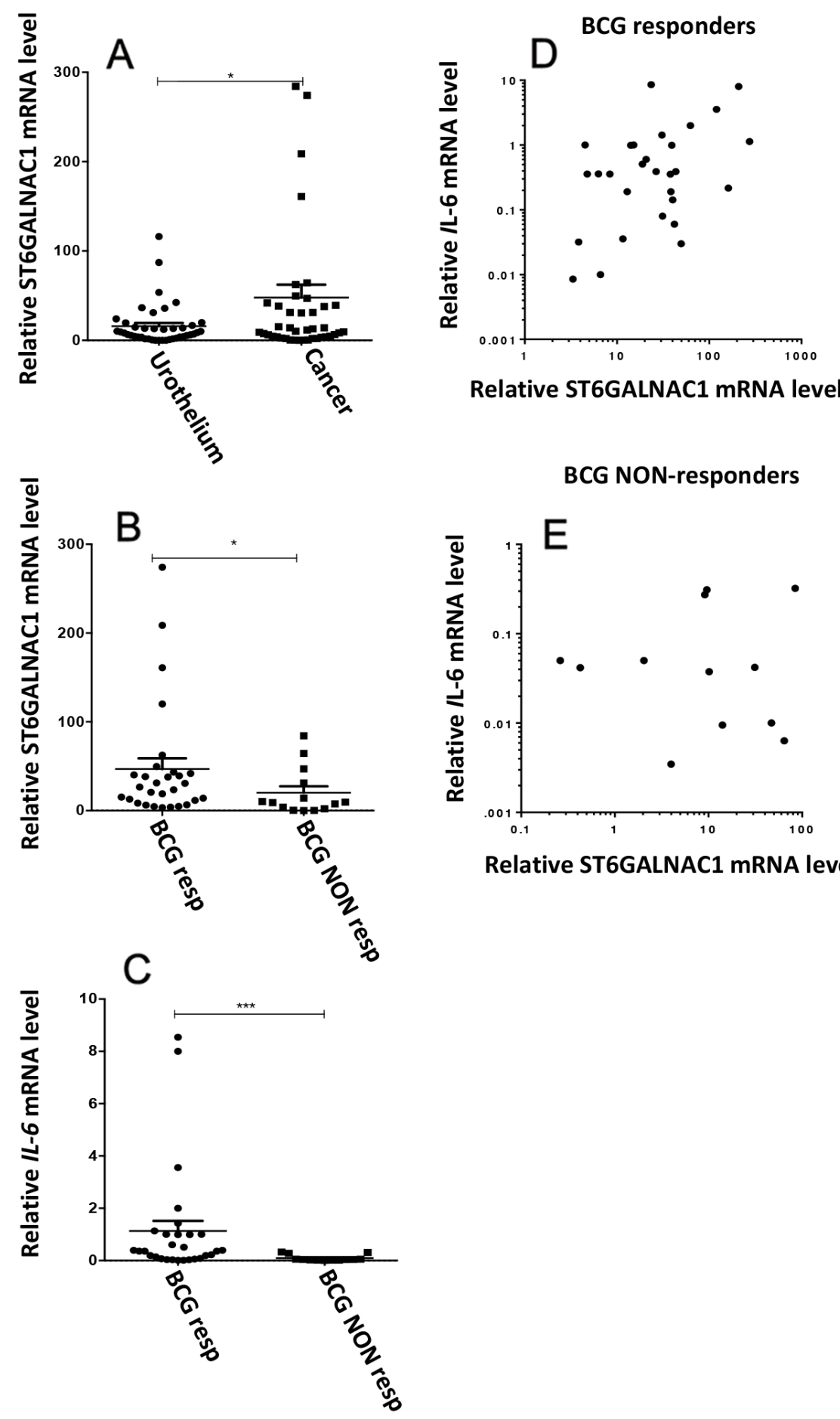

Relative ST6GALNAC1 mRNA level

Figure 2: Gene expression analysis of surgical specimens of bladder cancers and normal urothelium. Tissue specimens from 43 patients with nonmuscle-invasive bladder cancer eligible for BCG therapy, were collected, the RNA was extracted and the relative mRNA levels were analyzed by Real Time RT-PCR, as described in the Material and Methods section. Values indicate the number of mRNA molecules of ST6GALNAC1 or IL-6 genes per 1000 molecules of the reference gene ( $\beta$-actin). (A) The expression of ST6GALNAC1 mRNA was compared in tumor tissue and matched normal urothelium and found to be significantly higher ( $p<0.05$ according to Student's $t$ test for paired samples) in tumor. (B) Patients were divided according to their follow up after BCG treatment. BCG Responders (Resp) were considered those without recurrence within a minimal period of 12 months following TURBT. BCG non responders (NON-Resp) were those that experienced disease recurrence within that period. High ST6GALNAC1 mRNA patients all belonged to the Responders group. (C) The expression of IL-6 mRNA was measured in the two groups and found to be higher in the Responders group. (D and E) correlation analysis indicated a significant $(\mathrm{r}=0.375 ; \mathrm{p}=0.04)$ relationship between ST6GALNAC1 and IL-6 mRNA expression in the responders group (D) but not in the non-responders group (E) $(\mathrm{r}=0.281 ; \mathrm{p}=0.33)$. 
former genes were involved included apoptosis, cell growth, and angiogenesis, while the cancer-associated genes modulated toward decreased malignancy were involved in cell growth, cytoskeletal rearrangements and proteolytic activity (Supplementary Table 3). In addition, in $\mathrm{MCRs}_{\mathrm{Tn}}$ cells, a group of 5 genes (which became 12 when a $\log _{2}$ expression difference $\geq 0.5$ was used, fold change 1.4), collectively referred to as "caretaker genes" due to their role in preserving genomic stability, displayed down-regulation compared to $\mathrm{MCR}_{\mathrm{Nc}}$ (Table 1 and Supplementary Table 3).

It is expected that the co-ordinate down-regulation of genes involved in preserving genomic stability leads to the exacerbation of genotoxic stress. To obtain a "functional validation" of gene expression data, we compared the sensitivity of the two MCR cell lines to an oxidizing agent, such as $\mathrm{H}_{2} \mathrm{O}_{2}$. As shown in Figure 5 , the $\mathrm{H}_{2} \mathrm{O}_{2}$-induced cell death was dramatically higher in $\mathrm{MCR}_{\mathrm{sTn}}$ than in $\mathrm{MCR}_{\mathrm{Nc}}$, as shown by phase contrast microscopy (a) and cell counts (b).

\section{In MCR $_{\text {sTn }}$ cells BCG challenging up-regulates genes involved in post-transcriptional regulation}

To investigate the differential response to BCG of MCR cells expressing or not the sTn antigen, we analyzed the global gene expression of $\mathrm{MCR}_{\mathrm{sTn}}$ and $\mathrm{MCR}_{\mathrm{Nc}}$ after BCG challenge. We classified genes modulated by a $\log _{2}$ expression difference $\geq 1.0$ (which means a change of at least 2 folds) in broad functional categories (Supplementary Table 4). BCG challenge resulted in the modulation of a few genes which were different in the two MCR cell variants (Table 2 and Supplementary Table 4). The only gene expression change showing parallel modulation in $\mathrm{MCR}_{\mathrm{Nc}}$ and $\mathrm{MCR}_{\mathrm{sTn}}$ was the upregulation of $H L A-D Q A 2$, encoding the $\alpha 2$ chain of major histocompatibility complex class II DQ. The larger number of genes affected by BCG challenge, but only in $\mathrm{MCR}_{\mathrm{sTn}}$ cells, was involved in post-transcriptional regulation, including small nucleolar RNA (snoRNA) and small nuclear RNA (snRNA). This suggests that in $\mathrm{MCR}_{\mathrm{sTn}}$

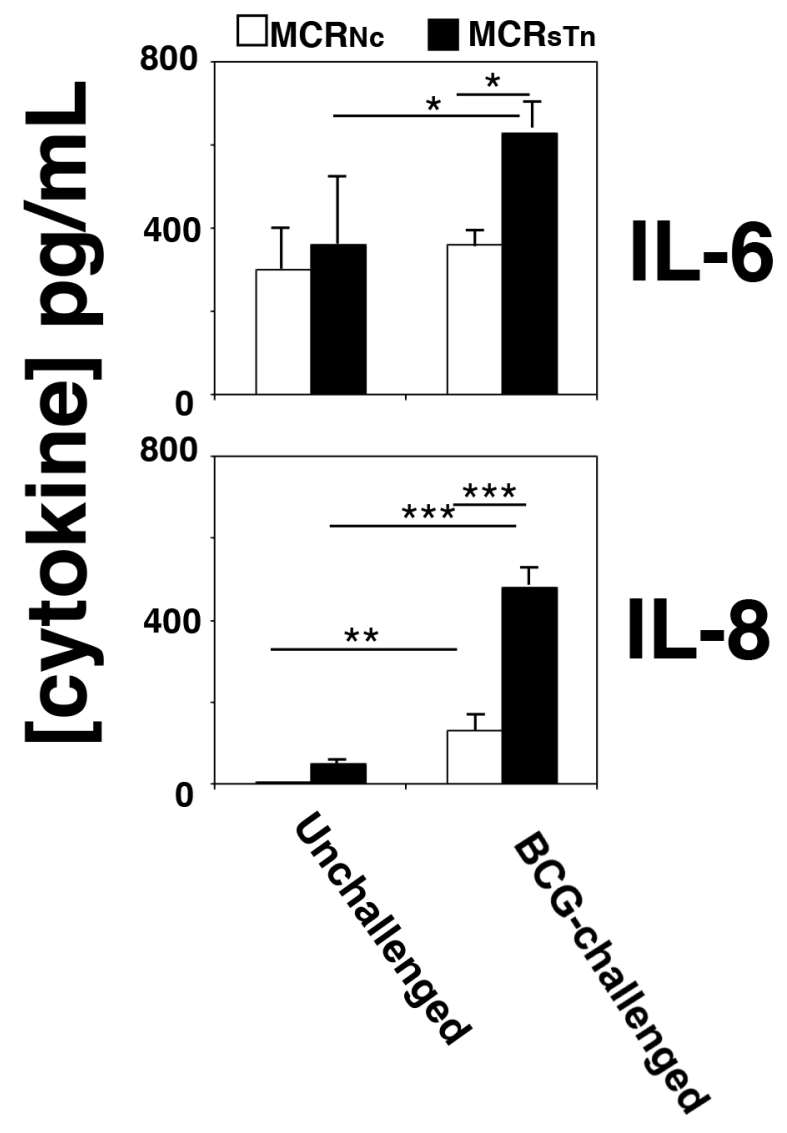

Figure 3: Cytokine secretion by BCG-challenged MCR cells. $\mathrm{MCR}_{\mathrm{Nc}}$ (white bars) and $\mathrm{MCR}_{\mathrm{sTn}}$ (black bars) cells were challenged or not with BCG and the concentration of ten cytokines secreted was determined in their conditioned media as described in the Materials and Methods section. Only IL-6 and IL- 8 were detectable and showed BCG modulation, mainly in $\mathrm{MCR}_{\mathrm{sTn}}$ cells. Data are the mean \pm SD of three experiments. ${ }^{* *} \mathrm{p}<0.0001 ; * * \mathrm{p}<0.001 ;{ }^{*} \mathrm{p}<0.05$, according to two ways ANOVA, followed by Tukey multiple comparison test. $p$ values are reported in Supplementary Table 1. 
cells, BCG challenge results in profound alterations of protein expression, in spite of the relatively low number of transcriptionally modulated genes. Other functional categories whose genes were affected only in $\mathrm{MCR}_{\text {sTn }}$ were within the proteolysis (up-regulation of one gene $\geq 3$ ) and signal transduction category (up-regulation of one gene $\geq 2$ ). The only functional category of genes which were affected only in $\mathrm{MCR}_{\mathrm{Nc}}$ was the cytoskeleton structure (down-regulation of one gene $\geq 2$ ).
Seven protein coding genes ( $L O X, M M E$, GLIPR1, NR2F1, PLCB1, RANBP2 and TMPRSS11E) and one RNA gene (SCARNA4) were chosen for validation of the microarray data by RT real time-PCR (Supplementary Figure 1). The two techniques provided consistent results for the seven protein coding genes, while some discrepancies were observed for SCARNA4. It is not clear whether this depends on the peculiar nature of this RNA gene and which of the two techniques provides more reliable results.

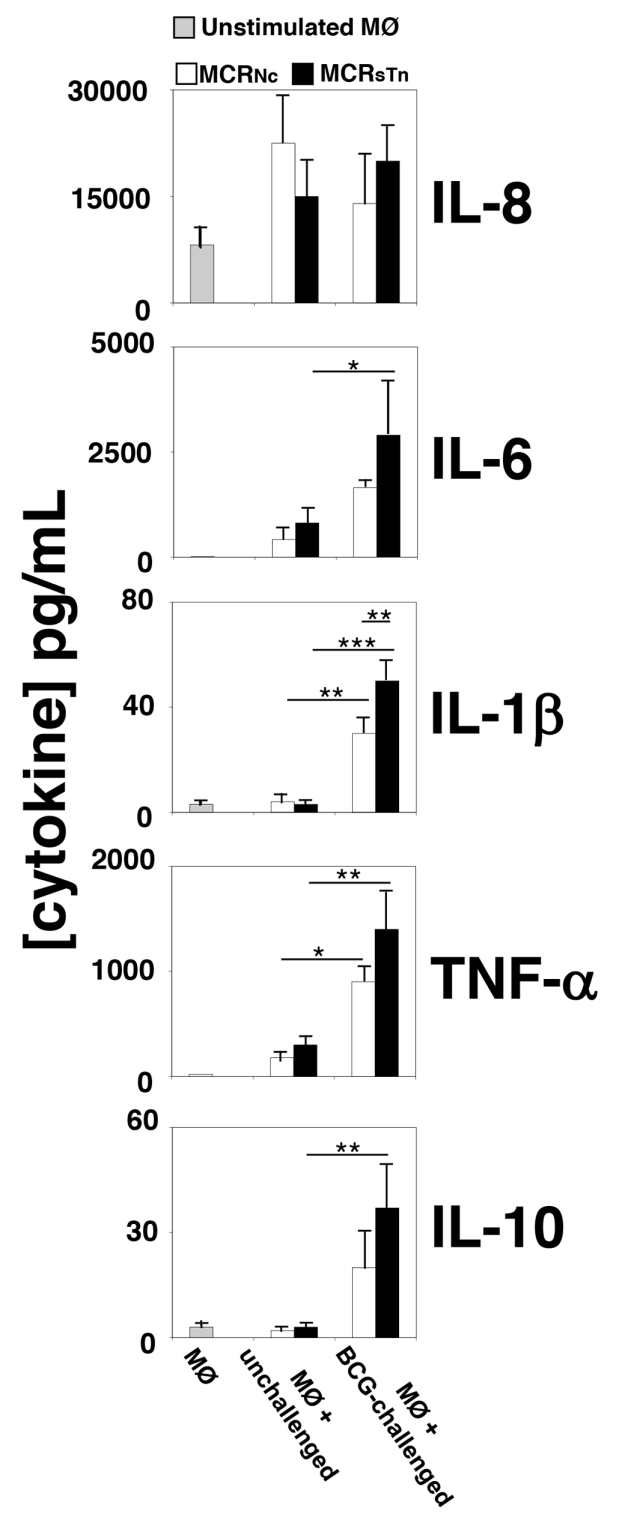

Figure 4: Cytokine secretion by macrophages treated with conditioned media of MCR cells. The secretion of ten cytokines was measured in the culture media of unstimulated macrophages or of macrophages stimulated with the conditioned media of $\mathrm{MCR}_{\mathrm{Nc}}$ (white bars) or $\mathrm{MCR}_{\mathrm{STn}}$ (black bars) either BCG-challenged or unchallenged, analyzed in Figure 3. Bars indicate the concentrations of cytokines detected in the conditioned medium of unstimulated macrophages (MØ, gray bars) or macrophages stimulated with conditioned media of unchallenged $\mathrm{MRC}_{\mathrm{Nc}}$ or $\mathrm{MCR}_{\mathrm{sTn}}$ cells (MØ + unchallenged) or stimulated with conditioned media of BCG-challenged MRC or $\mathrm{MCR}_{\mathrm{sTn}}$ cells (MØ + BCG-challenged). Macrophage stimulation by unchallenged cells was negligible. With the exception of IL-8, the conditioned medium of BCG-challenged $\mathrm{MCR}_{\mathrm{STn}}$ cells (black bars) potentiated cytokine release by macrophages more than that of $\mathrm{MCR}_{\mathrm{Nc}}$ (white bars). Data are the mean $\pm \mathrm{SD}$ of 3 experiments. ${ }^{* * *} p<0.0001 ; * * p<0.001 ;{ }^{*} p<0.05$, according to two ways ANOVA test, followed by Tukey multiple comparison test. $p$ values are reported in Supplementary Table 1. 
Table 1: Genes involved in maintaining chromosomal stability and/or DNA repair showing down-regulation in $\mathrm{MCR}_{\text {sTn }}$ cells.

\begin{tabular}{lccccc}
\hline $\begin{array}{l}\text { Genes involved } \\
\text { in preserving } \\
\text { chromosomal } \\
\text { stability }\end{array}$ & Fold change & $\begin{array}{c}\text { Genes involved } \\
\text { in homologous } \\
\text { recombination repair } \\
\text { (HR) }\end{array}$ & Fold change & $\begin{array}{c}\text { Genes involved } \\
\text { in nucleotide } \\
\text { excision repair } \\
\text { (NER) }\end{array}$ & Fold change \\
\hline HAUS6 & -2.1 & XRCC4 & -2.1 & $E R C C 6 L$ & -2.0 \\
SGOL1 & -2.0 & $B R C A 1$ & -2.0 & $E R C C 6$ & -1.7 \\
CSPP1 & -1.6 & XRCC2 & -1.6 & $E R C C 8$ & -1.5 \\
HAUS3 & -1.5 & & & & \\
KNTC1 & -1.5 & & & & \\
CDCA5 & -1.4 & & & & \\
\hline
\end{tabular}

\section{DISCUSSION}

Response to BCG is typically associated with upregulation of pro-inflammatory cytokines such as IL-6 $[19,20]$. In this study we have shown that BC patients responding to BCG-therapy express higher levels of IL-6 mRNAs and that a positive correlation exists between IL-6 and ST6GALNAC1 mRNA, but only among BCG responders. This, together with the fact that in our cohort high ST6GALNAC1 mRNA expressing patients were all $\mathrm{BCG}$ responders, provides a basis for the proposed role of sTn as a predictive biomarker for BCG response in BC [10]. To gain further mechanistic insights into the link between STn expression, malignancy and BCG response in $\mathrm{BC}$, we used a $\mathrm{BC}$ cell line transduced to overexpress the ST6GALNAC1 gene as an experimental model. Although the overexpression of ST6GALNAC1 has been widely studied in different cancer cell models and found to be responsible for increased malignancy [21-25], little is known about its role in $\mathrm{BC}$ biology [9].

While others have reported that BCG-challenge induces cytokine secretion by $\mathrm{BC}[1,20,26]$, our results show for the first time that this process is strongly stimulated by ST6GALNAC1/sTn expression. A significantly increased release of IL- 8 and IL- 6 was observed by the BCG-stimulated MCR cells expressing sTn $\left(\mathrm{MCR}_{\mathrm{STn}}\right)$, compared to the negative control cells $\left(\mathrm{MCR}_{\mathrm{Nc}_{\mathrm{c}}}\right)$. These pro-inflammatory cytokines are crucial for the activation and mobilization of immune effectors to the bladder urothelium, being therefore essential for the ultimate eradication of the tumor $[27,28]$.

Macrophages play a key role in determining the patient's response to BCG therapy. BCG effectiveness against $\mathrm{BC}$ cells implies the polarization of macrophages into M1phenotype, which drives the differentiation of helper $\mathrm{T}$ cells towards the pro-inflammatory Th1 response, leading to the activation of cytotoxic $\mathrm{T}$ cells. The hallmark of M1 is the secretion of pro-inflammatory cytokines, such as IL-6, IL- $1 \beta$ and TNF $\alpha$ and a low secretion of the anti- inflammatory cytokine IL-10. Notably, the macrophages stimulated with conditioned media from BCG-challenged $\mathrm{MCR}_{\text {sTn }}$ mainly secreted IL- 6, IL- 8 and TNF- $\alpha$ but very little IL-10, suggesting a phenotype closer to the proinflammatory type M1 than to the anti-inflammatory type M2 [29]. This is of particular relevance considering the association of a poor response to BCG with the presence of M2 type macrophages [30]. Moreover, these results provide key information that can explain why the expression of STn and of sialyl-6-T antigens (the biosynthesis of the former is mainly dependent on ST6GALNAC1 while that of the latter depends mainly on ST6GALNAC2, Figure 1) [11] by BC is predictive of $B C G$ response and is associated with a better recurrencefree survival [10]. On the other hand, $\mathrm{MCR}_{\mathrm{STn}}$ cells (not challenged with BCG) and sTn-expressing mucins induce a tolerogenic phenotype in human dendritic cells and in T-lymphocytes, respectively [13, 31]. Together, these data suggest that BCG treatment turns the expression of sTn/sialyl-6-T from an unfavorable condition associated with increased progression and immune evasion into a favorable prognostic marker of a better response to $\mathrm{BCG}$ therapy.

The link between STn expression and malignancy in bladder cancer was further investigated through an exhaustive analysis of the ST6GALNACl-induced transcriptome modulation via gene expression microarray technology. We observed a prevalence of changes oriented toward increased malignancy in $\mathrm{MCR}_{\mathrm{STn}}$, including modulation of genes controlling cell growth and/or apoptosis, which is consistent with the reported increased proliferation rate of $\mathrm{MCR}_{\mathrm{STn}[9]}$. However, the most prominent transcriptomic change induced by the constitutive overexpression of ST6GALNAC1 in MCR cells was the decreased expression of genes involved in maintaining genomic stability. Consistently, we observed a dramatically higher sensitivity to $\mathrm{H}_{2} \mathrm{O}_{2}$-induced cell damage of $\mathrm{MCR}_{\mathrm{sTn}}$ in comparison with $\mathrm{MCR}_{\mathrm{Nc}}$. This is of particular interest if one considers that the generation of 
reactive oxygen species by $\mathrm{BCG}$ is a crucial mechanism of BCG-induced damage to BC cells [4]. Thus, it is possible that an increased sensitivity to oxidizing agents by sTnexpressing bladder cancers is one of the basis of their better response to BCG therapy.

Although the secretion of cytokines IL-6 and IL-8 displayed a marked increase in MCR cells after BCG challenge, we failed to observe a consistent up-regulation of their genes. As a possible explanation, it should be considered that in some circumstances the secretion of cytokines is regulated by the release of preformed molecules stored in vesicles, rather than by de novo transcription of their genes [32].

The challenge with BCG modulated a higher number of genes in $\mathrm{MCR}_{\mathrm{sTn}}$ cells than in $\mathrm{MCR}_{\mathrm{Nc}}$ cells, suggesting that the presence of the sTn antigen on membrane glycoproteins affects the development of the genetic program triggered by BCG contact. A low number of protein coding genes were modulated by BCG, while a high number of non-coding RNA genes were up-regulated, but only in the $\mathrm{MCR}_{\mathrm{sTn}}$ variant. The majority of these RNA genes belonged to the group of small nucleolar RNAs which guide the methylation or pseudouridylation of other RNAs [33, 34], regulating protein expression. It is possible that through these non-coding RNAs, BCG has a higher ability to modulate the proteome of sTn-expressing $\mathrm{BC}$ cells, including secretion of cytokines.

Although the results we obtained with this cell line should be generalized with great caution, we have shown that in BC cells sTn expression can induce changes of gene expression putatively associated with increased malignancy. Furthermore, the down-regulation of genes
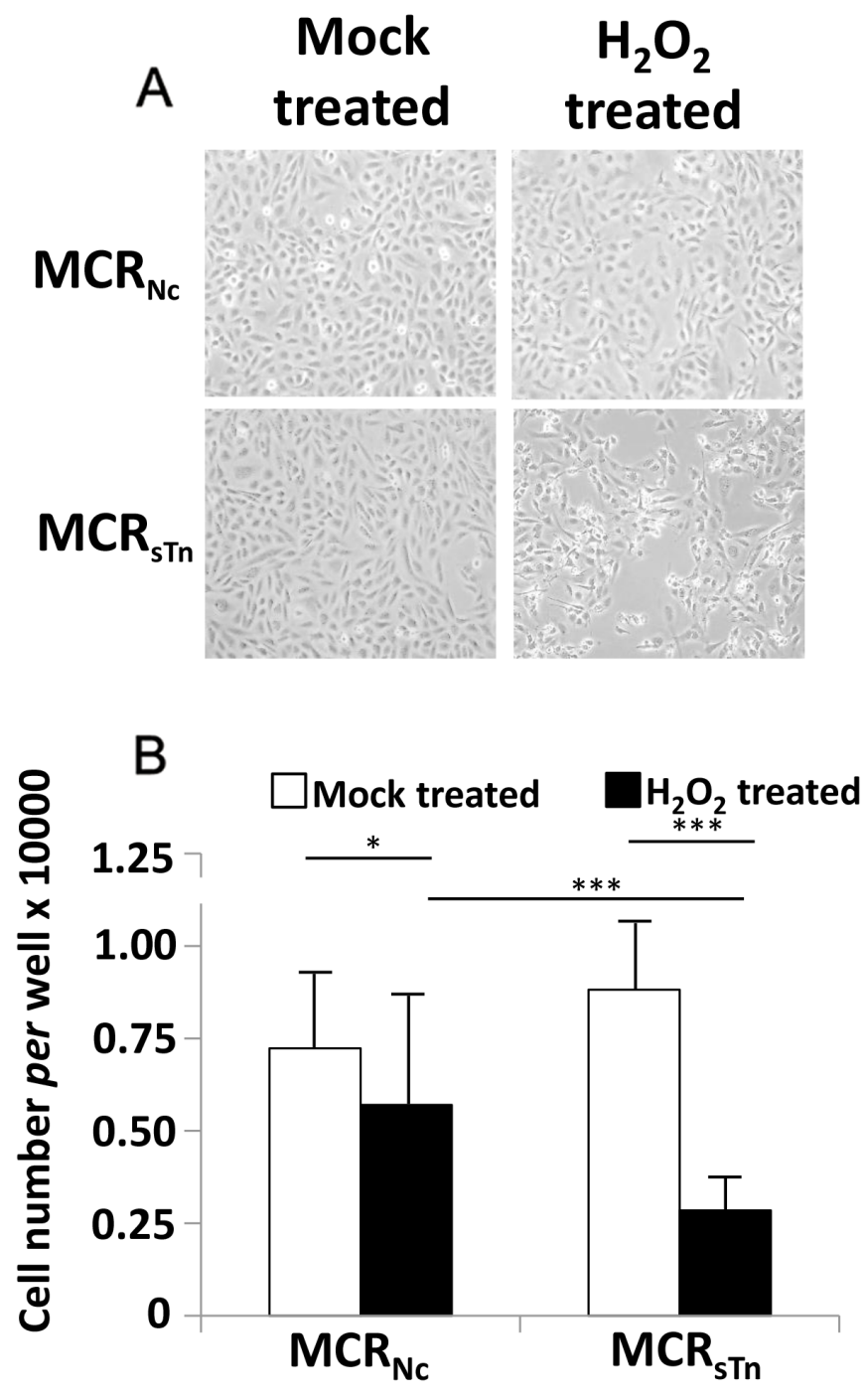

Figure 5: Cytotoxic effect of $\mathbf{H}_{2} \mathrm{O}_{2}$. (A) Cells were treated with $\mathrm{H}_{2} \mathrm{O}_{2}$ or mock-treated as described in Materials and Methods and photographed with a phase contrast microscope (original magnification $40 \mathrm{X}$ ). (B) Cell counting indicated a $20 \%$ reduction in $\mathrm{MCR}_{\mathrm{Nc}}$ cells and a $68 \%$ reduction in $\mathrm{MCR}_{\mathrm{STn}}$ after $\mathrm{H}_{2} \mathrm{O}_{2}$ treatment. Data are the mean $\pm \mathrm{SD}$ of at least three experiments performed in triplicate. $* p<$ 0.05 ; *** $p<0.0001$ according to Student's $t$ test. 
Table 2: Modulation of gene expression by BCG challenge.

Functional Class
Cell Growth and Survival
Cytoskeleton Structure
Inflammatory and Immune Response
Intracellular Transport
Postranscriptional Regulation
Signal Transduction
Transcription regulation

Genes showing a fold change $\geq 2$ upon BCG challenging were classified in broad functional categories. Each square represents a gene modulated by BCG according to this code: $\square$ up-regulation $\geq 4$ (fold changes); $\square$ up-regulation $\geq 3,<4$; $\square$ up-regulation $\geq 2,<3 ; \square$ down-regulation $\geq 2,<3 ; \square$ down-regulation $\geq 3,<4 ; \square$ down-regulation $\geq 4$.

responsible for genomic stability results in increased sensitivity to oxidizing agents, like those produced by BCG infection. This, together with the induction of an increased inflammatory response by macrophages, can explain why the expression of the sTn antigen by BC cells can be a predictive marker for a successful BCG therapy.

\section{MATERIALS AND METHODS}

\section{Surgical specimens}

Matched pairs of histologically verified nonmuscle-invasive bladder cancers (multiple tumors primary or recurrent) and normal appearing mucosa remote from the tumor were collected from 43 patients, at Hospital São José (Lisbon, Portugal). Tissue samples were immediately immersed in RNAlater ${ }^{\circledR}$ RNA Stabilization Reagent (Sigma), stored at $4^{\circ} \mathrm{C}$, overnight and then preserved until further processing at $-20^{\circ} \mathrm{C}$. Patients were treated with transurethral resection of the bladder tumors (TURBT) followed by BCG instillations (TICE® BCG). None of these patients had received previous adjuvant therapy. Prior patient consent and approval from the institute research ethics committee were obtained. According to recurrence, we named "BCG responders" those patients without recurrence at least until one year after TURBT (29 patients) and "BCG non-responders" those experiencing recurrence within one year after TURBT (14 patients).

\section{ST6GALNAC1-expressing MCR cells}

The cell line MCR, obtained from a subcutaneous metastatic lesion of an invasive transitional cell cancer of the bladder [35], was grown in DMEM (4.5 g/L glucose), containing 10\% Foetal Calf Serum (FCS), $2 \mathrm{mM} \mathrm{L-}$ glutamine and $100 \mu \mathrm{g} / \mathrm{mL}$ penicillin/streptomycin, all from Sigma. Transduction with a ST6GALNAC1-expressing lentiviral vector was described elsewhere [9]. The transduced MCR cells were enriched in their sTn positive population $\left(\mathrm{MCR}_{\mathrm{STn}}\right)$, by magnetic-activated cell sorting as recommended by the manufacturer (Miltenyi Biotec), using anti-sTn antibody (HB-STn1 clone, Dako).

\section{Real time RT-PCR}

Total RNA was isolated using the GenElute Mammalian Total RNA Purification kit (Sigma), according to the manufacturer's instructions. One microgram of total RNA was reverse transcribed using the randomprimers based High Capacity cDNA Archive Kit (Applied Biosystems). The expression level of ST6GALNAC1 (Hs00300842_m1) IL-6 (Hs00174131_m1), LOX (Hs00942480_m1), MME (Hs00153510_m1), GLIPR1 (Hs01564142_m1), NRF2 (Hs01354342_mH), SCARNA4 (Hs03298714_s1), PLCB1 (Hs01001930_m1), RANBP2 (Hs00196669 m1) and TMPRSS11E (Hs01070171 m1) was evaluated with the TaqMan assay system in a 7500 Fast Real-Time PCR System (Applied Biosystems) using 
the TaqMan Universal PCR Master Mix Fast, as described previously $[13,36,37]$. The efficiency of the amplification reaction for each primer-probe was above 95\% (as determined by the manufacturer). Normalized mRNA expression was computed as number of mRNA molecules of the gene of interest per 1000 mRNA molecules of the endogenous control $\beta$-actin gene, calculated using the 2 $\Delta \mathrm{CT} \times 1000$ formula [38].

\section{BCG challenge of MCR cells}

Commercial Connaught BCG (ImmuCyst, Sanofi Pasteur SA, France) was suspended in PBS containing $0.05 \%$ Tween 80 and stored at $-80{ }^{\circ} \mathrm{C}$. Before each assay, BCG aggregates were discarded by centrifugation $(300 \times$ $\mathrm{g}$ for $5 \mathrm{~min})$. To assess BCG internalization, bacteria were stained with $2 \mu \mathrm{g} / \mathrm{mL}$ of 5-(and-6-)(((4-chloromethyl) benzoyl)amino)tetramethylrhodamine (CMTR, Invitrogen) for $2 \mathrm{~h}$ in culture medium, incubated with $\mathrm{MCR}_{\mathrm{Nc}}$ or $\mathrm{MCR}_{\mathrm{sTn}}$ cells in a $1: 10$ cell/bacteria ratio for $2 \mathrm{~h}$ at 37 ${ }^{\circ} \mathrm{C}$ and analyzed by flow cytometry. To assess cytokine secretion, $\mathrm{MCR}_{\mathrm{Nc}}$ or $\mathrm{MCR}_{\mathrm{sTn}}$ cells were challenged with unstained BCG for $2 \mathrm{~h}$ at $37^{\circ} \mathrm{C}$, the medium was removed and the cells were washed twice with PBS and incubated with fresh medium for $16 \mathrm{~h}$. Conditioned media were used for cytokine analysis and to challenge macrophages, while cell pellets were used for RNA extraction and transcriptomic analysis.

\section{Determination of cytokine concentration}

The concentration of cytokines IL-1 $\beta$, IL-2, IL4, IL-6, IL-8, IL-10, IL-12, IL-17, IFN $\gamma$ and TNF $\alpha$ was measured in a 96-well strip plate from a commercial MIBA kit (Bio-Rad), as recommended by manufacturer's instructions. Fluorescence was read in a Luminex 100 Bio-Plex Liquid Array Multiplexing System reader (Bio$\mathrm{Rad})$ and the data analyzed with the Bio-Plex Manager v5 software (Bio-Rad).

\section{Macrophage preparation and stimulation}

Mononuclear cells were isolated by Ficoll-Hypaque density gradient centrifugation (GE Healthcare) from the peripheral blood of healthy blood-donors, obtained from the Blood Collection Service of the Pizzardi Hospital of Bologna, according to the requirements of the local ethical committee. Macrophages were obtained by differentiation of monocytes by culture in RPMI 1640 (Sigma) medium supplemented with 20\% FCS, $2 \mathrm{mM}$ L-glutamine and $100 \mu \mathrm{g} / \mathrm{mL}$ penicillin/streptomycin. After 7 days, monocyte-derived macrophages were detached with a cell scraper and dispensed in 24 well plates at a cell density corresponding approximately to $50 \%$ of confluence. One day later, macrophages were incubated with standard unconditioned culture medium or with the media conditioned by $\mathrm{MCR}_{\mathrm{Nc}}$ or $\mathrm{MCR}_{\mathrm{sTn}}$ cells either BCG-challenged (as described above) or mock challenged. After $2 \mathrm{~h}$, the conditioned media were replaced by fresh medium, which was collected $24 \mathrm{~h}$ later and stored at $-80{ }^{\circ} \mathrm{C}$ for the detection of cytokines secreted by macrophages.

\section{Whole transcriptome analysis by expression microarray}

Total RNA was isolated by the guanidinium thiocyanate-method [39] and converted to labelled single strand cDNA (ssDNA) by the commercial Whole Transcript Expression kit (Ambion), according to the manufacturer's instructions. Labelled ssDNA fragments were hybridized in a Human Transcriptome Array 2.0 overnight. After staining with phycoerythrin-streptavidin, fluorescence was read in a GeneChip Scanner 3000 7G (Affymetrix). Raw data were background-subtracted, normalized and summarized with the robust multi-array average (RMA) algorithm implemented in the Affy package of Bioconductor (http://www.bioconductor.org). Differentially expressed genes between query and control assay were selected by application of the $t$-test with a $\mathrm{p} \leq 0.05$ cut-off and by the $\log _{2}$ expression ratio, considering only variations $\geq 0.5$. Array data were analyzed by the ArrayStar v2.0 software (DNASTAR) and through a literature search of the biological roles of modulated genes. Gene nomenclature followed the HUGO Gene Nomenclature Committee rules (http://www.genenames.org/) in italic uppercase letters. With exception of cytokines, proteins had the same name as the gene, represented in regular uppercase.

\section{$\mathrm{H}_{2} \mathrm{O}_{2}$ treatment}

Cells were incubated for $1 \mathrm{~h}$ in serum-free medium without $\mathrm{H}_{2} \mathrm{O}_{2}$ (control treatment) or with $5 \mathrm{mM} \mathrm{H}_{2} \mathrm{O}_{2}$. Cells were then rinsed, grown for $24 \mathrm{~h}$ in complete medium, harvested, stained with trypan blue and counted.

\section{Abbreviations}

BC: bladder cancer; BCG: Bacillus CalmetteGuérin; CMTR: 5-(and-6)-(((4-chloromethyl)benzoyl) amino)tetramethylrhodamine; DMEM: Dulbecco's modified Eagle medium; FCS: foetal calf serum; Gal: Galactose; GalNAc: N-acetylgalactosamine; GlcNAc: $\mathrm{N}$-acetylglucosamine; MIBA: multiplex immune-beads assay; PE: phycoerythrin; RPMI: Roswell Park Memorial Institute; RT-PCR: reverse transcriptase-polymerase chain reaction; Sia: sialic acid; sTn: sialyl-Tn; TURBT: transurethral resection of the bladder tumors.

\section{Author contribution}

P.F.S and M.S. performed the bulk of the experimental work, analysed data and helped writing the 
manuscript. M. Car, G.V., and M. Cat performed part of the experimental work. N.M. and M. Chir. contributed to the establishment of transduced cell lines. A.A. performed microarray experiments and analysed microarray data. P.A.V. and F.D conceived the work, analysed the data and wrote the manuscript. All authors revised critically the manuscript, have given final approval of the version to be published and agree to be accountable for all aspects of the work in ensuring that questions related to the accuracy or integrity of any part of the work are appropriately investigated and resolved.

\section{ACKNOWLEDGMENTS}

We thank Dr. Francesca Borsetti and Dr. Enzo Spisni, BIGEA Department of the University of Bologna for their help with the multiplex immune-beads assays.

\section{CONFLICTS OF INTEREST}

The Authors declare that there are no conflicts of interests.

\section{FUNDING}

This work was supported by: Portuguese Foundation for Science and Technology (FCT) $\mathrm{PhD}$ grants SFRH/BD/45120/2008 (Paulo F. Severino), SFRH/BD/81860/2011 (Mariana Silva) and SFRH/ BD/100970/2014 (Mylène Carrascal), Liga Portuguesa Contra o Cancro 2011 (Mylène A. Carrascal); Prémio Inovação Universidade de Coimbra and the Santander Totta/ Universidade NOVA de Lisboa prizes (Paula Videira). Grants from the University of Bologna (Fabio Dall'Olio). Mariangela Catera and Giulia Venturi are PhD students supported by grants from the University of Bologna.

\section{REFERENCES}

1. Bevers RF, Kurth KH, Schamhart DH. Role of urothelial cells in BCG immunotherapy for superficial bladder cancer. Br J Cancer. 2004; 91:607-12.

2. Videira PA, Calais FM, Correia M, Ligeiro D, Crespo HJ, Calais F, Trindade H. Efficacy of bacille Calmette-Guérin immunotherapy predicted by expression of antigenpresenting molecules and chemokines. Urology. 2009; 74:944-50.

3. Carretero R, Cabrera T, Gil H, Saenz-Lopez P, Maleno I, Aptsiauri N, Cozar JM, Garrido F. Bacillus Calmette-Guerin immunotherapy of bladder cancer induces selection of human leukocyte antigen class I-deficient tumor cells. Int J Cancer. 2011; 129:839-46.

4. Shah G, Zielonka J, Chen F, Zhang G, Cao Y, Kalyanaraman $\mathrm{B}$, See W. $\mathrm{H} 2 \mathrm{O} 2$ generation by bacillus Calmette-Guérin induces the cellular oxidative stress response required for bacillus Calmette-Guérin direct effects on urothelial carcinoma biology. J Urol. 2014; 192:1238-48.

5. Dall'Olio F, Malagolini N, Trinchera M, Chiricolo M. Mechanisms of cancer-associated glycosylation changes. Front Biosci (Landmark Ed). 2012; 17:670-99.

6. Pinho SS, Reis CA. Glycosylation in cancer: mechanisms and clinical implications. Nat Rev Cancer. 2015; 15:540-55.

7. Ohyama C. Glycosylation in bladder cancer. Int J Clin Oncol. 2008; 13:308-13.

8. Yang G, Tan Z, Lu W, Guo J, Yu H, Yu J, Sun C, Qi X, Li Z, Guan F. Quantitative glycome analysis of N-glycan patterns in bladder cancer vs normal bladder cells using an integrated strategy. J Proteome Res. 2015; 14:639-53.

9. Ferreira JA, Videira PA, Lima L, Pereira S, Silva M, Carrascal M, Severino PF, Fernandes E, Almeida A, Costa C, Vitorino R, Amaro T, Oliveira MJ, et al. Overexpression of tumour-associated carbohydrate antigen sialyl-Tn in advanced bladder tumours. Mol Oncol. 2013; 7:719-31.

10. Lima L, Severino PF, Silva M, Miranda A, Tavares A, Pereira S, Fernandes E, Cruz R, Amaro T, Reis CA, Dall'Olio F, Amado F, Videira PA, et al. Response of high-risk of recurrence/progression bladder tumours expressing sialyl-Tn and sialyl-6-T to BCG immunotherapy. Br J Cancer. 2013; 109:2106-14.

11. Marcos NT, Pinho S, Grandela C, Cruz A, Samyn-Petit B, Harduin-Lepers A, Almeida R, Silva F, Morais V, Costa J, Kihlberg J, Clausen H, Reis CA. Role of the human ST6GalNAc-I and ST6GalNAc-II in the synthesis of the cancer-associated sialyl-Tn antigen. Cancer Res. 2004; 64:7050-57.

12. Tamura F, Sato Y, Hirakawa M, Yoshida M, Ono M, Osuga T, Okagawa Y, Uemura N, Arihara Y, Murase K, Kawano Y, Iyama S, Takada K, et al. RNAi-mediated gene silencing of ST6GalNAc I suppresses the metastatic potential in gastric cancer cells. Gastric Cancer. 2016; 19:85-97.

13. Carrascal MA, Severino PF, Guadalupe Cabral M, Silva M, Ferreira JA, Calais F, Quinto H, Pen C, Ligeiro D, Santos LL, Dall'Olio F, Videira PA. Sialyl Tn-expressing bladder cancer cells induce a tolerogenic phenotype in innate and adaptive immune cells. Mol Oncol. 2014; 8:753-65.

14. Dall'Olio F, Chiricolo M. Sialyltransferases in cancer. Glycoconj J. 2001; 18:841-50.

15. Dall'Olio F, Malagolini, N, Trinchera, M, Chiricolo, M. Sialosignaling: Sialyltransferases as engines of self-fueling loops in cancer progression. Biochim Biophys Acta. 2014; 1840: 2752-2764.

16. Loureiro LR, Carrascal MA, Barbas A, Ramalho JS, Novo C, Delannoy P, Videira PA. Challenges in Antibody Development against $\mathrm{Tn}$ and Sialyl-Tn Antigens. Biomolecules. 2015; 5:1783-809.

17. Munkley J, Oltean S, Vodák D, Wilson BT, Livermore KE, Zhou Y, Star E, Floros VI, Johannessen B, Knight B, McCullagh P, McGrath J, Crundwell M, et al. The androgen 
receptor controls expression of the cancer-associated sTn antigen and cell adhesion through induction of ST6GalNAc1 in prostate cancer. Oncotarget. 2015; 6:34358-74. doi: 10.18632/oncotarget.6024.

18. Costa C, Pereira S, Lima L, Peixoto A, Fernandes E, Neves D, Neves M, Gaiteiro C, Tavares A, Gil da Costa RM, Cruz R, Amaro T, Oliveira PA, et al. Abnormal Protein Glycosylation and Activated PI3K/Akt/mTOR Pathway: role in Bladder Cancer Prognosis and Targeted Therapeutics. PLoS One. 2015; 10:e141253.

19. Cai T, Nesi G, Mazzoli S, Meacci F, Tinacci G, Luciani LG, Ficarra V, Malossini G, Bartoletti R. Prediction of response to bacillus Calmette-Guérin treatment in non-muscle invasive bladder cancer patients through interleukin- 6 and interleukin-10 ratio. Exp Ther Med. 2012; 4:459-64.

20. Chen FH, Crist SA, Zhang GJ, Iwamoto Y, See WA. Interleukin-6 production by human bladder tumor cell lines is up-regulated by bacillus Calmette-Guérin through nuclear factor-kappaB and Ap-1 via an immediate early pathway. J Urol. 2002; 168:786-97.

21. Julien S, Lagadec C, Krzewinski-Recchi MA, Courtand G, Le Bourhis X, Delannoy P. Stable expression of sialyl-Tn antigen in T47-D cells induces a decrease of cell adhesion and an increase of cell migration. Breast Cancer Res Treat. 2005; 90:77-84

22. Julien S, Adriaenssens E, Ottenberg K, Furlan A, Courtand G, Vercoutter-Edouart AS, Hanisch FG, Delannoy P, Le Bourhis X. ST6GalNAc I expression in MDA-MB-231 breast cancer cells greatly modifies their O-glycosylation pattern and enhances their tumourigenicity. Glycobiology. 2006; 16:54-64.

23. Julien S, Krzewinski-Recchi MA, Harduin-Lepers A, Gouyer V, Huet G, Le Bourhis X, Delannoy P. Expression of sialyl-Tn antigen in breast cancer cells transfected with the human CMP-Neu5Ac: GalNAc alpha2,6-sialyltransferase (ST6GalNac I) cDNA. Glycoconj J. 2001; 18:883-93.

24. Sewell R, Bäckström M, Dalziel M, Gschmeissner S, Karlsson H, Noll T, Gätgens J, Clausen H, Hansson GC, Burchell J, Taylor-Papadimitriou J. The ST6GalNAc-I sialyltransferase localizes throughout the Golgi and is responsible for the synthesis of the tumor-associated sialyl-Tn O-glycan in human breast cancer. J Biol Chem. 2006; 281:3586-94.

25. Pinho S, Marcos NT, Ferreira B, Carvalho AS, Oliveira MJ, Santos-Silva F, Harduin-Lepers A, Reis CA. Biological significance of cancer-associated sialyl-Tn antigen: modulation of malignant phenotype in gastric carcinoma cells. Cancer Lett. 2007; 249:157-70.

26. Bevers RF, de Boer EC, Kurth KH, Schamhart DH. BCGinduced interleukin- 6 upregulation and BCG internalization in well and poorly differentiated human bladder cancer cell lines. Eur Cytokine Netw. 1998; 9:181-86.

27. Kresowik TP, Griffith TS. Bacillus Calmette-Guerin immunotherapy for urothelial carcinoma of the bladder. Immunotherapy. 2009; 1:281-88.

28. Lockyer CR, Gillatt DA. BCG immunotherapy for superficial bladder cancer. J R Soc Med. 2001; 94:119-23.

29. Mantovani A, Allavena P, Sica A, Balkwill F. Cancer-related inflammation. Nature. 2008; 454:436-44.

30. Lima L, Oliveira D, Tavares A, Amaro T, Cruz R, Oliveira MJ, Ferreira JA, Santos L. The predominance of M2-polarized macrophages in the stroma of low-hypoxic bladder tumors is associated with BCG immunotherapy failure. Urol Oncol. 2014; 32:449-57.

31. Beatson R, Maurstad G, Picco G, Arulappu A, Coleman J, Wandell HH, Clausen H, Mandel U, Taylor-Papadimitriou J, Sletmoen M, Burchell JM. The Breast Cancer-Associated Glycoforms of MUC1, MUC1-Tn and sialyl-Tn, Are Expressed in COSMC Wild-Type Cells and Bind the C-Type Lectin MGL. PLoS One. 2015; 10:e125994.

32. Stanley AC, Lacy P. Pathways for cytokine secretion. Physiology (Bethesda). 2010; 25:218-29.

33. Galardi S, Fatica A, Bachi A, Scaloni A, Presutti C, Bozzoni I. Purified box C/D snoRNPs are able to reproduce sitespecific 2'-O-methylation of target RNA in vitro. Mol Cell Biol. 2002; 22:6663-68.

34. Kiss-László Z, Henry Y, Bachellerie JP, Caizergues-Ferrer M, Kiss T. Site-specific ribose methylation of preribosomal RNA: a novel function for small nucleolar RNAs. Cell. 1996; 85:1077-88.

35. Zoli W, Ricotti L, Tesei A, Ulivi P, Gasperi Campani A, Fabbri F, Gunelli R, Frassineti GL, Amadori D. Scheduledependent cytotoxic interaction between epidoxorubicin and gemcitabine in human bladder cancer cells in vitro. Clin Cancer Res. 2004; 10:1500-07.

36. Videira PA, Correia M, Malagolini N, Crespo HJ, Ligeiro D, Calais FM, Trindade H, Dall'Olio F. ST3Gal.I sialyltransferase relevance in bladder cancer tissues and cell lines. BMC Cancer. 2009; 9:357.

37. Crespo HJ, Cabral MG, Teixeira AV, Lau JT, Trindade $\mathrm{H}$, Videira PA. Effect of sialic acid loss on dendritic cell maturation. Immunology. 2009; 128:e621-31.

38. Meijerink J, Mandigers C, van de Locht L, Tönnissen E, Goodsaid F, Raemaekers J. A novel method to compensate for different amplification efficiencies between patient DNA samples in quantitative real-time PCR. J Mol Diagn. 2001; 3:55-61.

39. Chomczynski P, Sacchi N. Single-step method of RNA isolation by acid guanidinium thiocyanate-phenol-chloroform extraction. Anal Biochem. 1987; 162:156-59. 